\title{
Artigo de revisão: \\ Os fundamentos da aprendizagem baseada em design: uma estratégia multidimensional apropriada à abordagem de problemas do mundo contemporâneo
}

Bianca M. R. Martins (UniCarioca/NUCAP/PUC-Rio)

\section{Resumo}

Neste artigo, discutem-se os paradigmas emergentes do contexto educacional brasileiro, enfatizando sua natureza construtivista, interacionista, sociocultural e transcendente. Um cenário propício à postulação de práticas de aprendizagem integradoras de conhecimentos multidimensionais, flexíveis, emancipadoras, colaborativas, atentas às necessidades do contexto próximo à escola. Procuramos localizar neste contexto a importância da elaboração da subjetividade, levando em conta que a interseção entre a construção do real e a construção do sujeito é favorecida pelo processo de desenvolvimento de um objeto projetado. Procuramos evidenciar que o ato de projetar deve receber atenção especial no ensino fundamental. Estudamos, também, o processo de tomada de consciência como justificativa para a relevância da Aprendizagem Baseada em Design durante o Ensino Fundamental, pois, a partir deste conceito, fica claro que não é somente um objeto que conduz a criança à fase de compreensão. É necessário imaginar cenários ou problemas que favoreçam a criança a transformar os esquemas de ação prévios em apreensões de noções e operações. Investigamos, ainda, as aprendizagens ativas, tais como Aprendizagem Baseada em Problemas e Aprendizagem Baseada em Projetos, como propostas pedagógicas em sintonia com a formação de indivíduos com uma visão global da realidade, vinculando a aprendizagem a situações e problemas reais e preparando-os para a aprendizagem ao longo da vida. Após, fazemos uma análise das características da Aprendizagem Baseada em Design evidenciando-a como estratégia educativa que favorece a abordagem multidimensional apropriada à resolução problemas do mundo contemporâneo, o trabalho em equipe, a proposta de solução desenvolvida em cooperação com o usuário, a utilização de ferramentas de gestão e plano de ação, ambas importantes para a vida adulta, a interdisciplinaridade, aguçando o senso estético e, por fim, a imaginação de soluções esboçando ideias para ações futuras.

Palavras-chave: Design, Pedagogia, Aprendizagem Baseada em Design, Design na escola

\begin{abstract}
This paper discusses the emerging paradigms of the Brazilian educational context emphasizing its constructivist, interactional, sociocultural and transcendent nature. It is a scenario favorable to postulation of integrative learning practices of multidimensional knowledge, flexible, empowerment, collaborative, taking local needs close to school.

We seek to show that the act of designing should receive special attention in elementary school. We also studied the awareness process to justify the relevance Design-Based Learning for the elementary school, because from this concept it is clear that it is not only an object that brings the child to the stage of understanding. You must imagine scenarios or problems that encourage the child to turn the previous action schemes in apprehension of notions and operations. We also investigate active learnings in line with the formation of individuals with a global vision of reality, linking learning to real situations and preparing them for the lifelong learning. After, we make an analysis of Design-Based Learning features showing it as an educational strategy that favors: appropriate multidimensional approach to solving problems of the contemporary world; teamwork; proposed
\end{abstract}


solution developed in cooperation with the user; use of management tools and action plans; interdisciplinarity, sharpening the aesthetic sense and imagination solutions sketching ideas for future actions.

Keywords: Design, Pedagogy, Design-Based Learning, Design in school

\section{Introdução e enfoque metodológico}

O presente artigo faz parte de uma pesquisa mais ampla de cunho qualitativo, exploratório e propositivo a respeito da inserção da Aprendizagem baseada em Design na Escola. Para investigar a validade desta proposta, apresentamos aqui uma revisão de literatura a respeito - pesquisa bibliográfica e documental, para identificar a relevância desta abordagem para a Educação Fundamental contemporânea. Para tal, serão discutidos os paradigmas do contexto educacional emergente (MORAES, 2005), enfatizando sua natureza construtivista, interacionista, sociocultural e transcendente. Um cenário propício à postulação de práticas de aprendizagem integradoras de conhecimentos multidimensionais, flexíveis, emancipadoras, colaborativas, atentas às necessidades do contexto próximo à escola. A partir de então, procuramos localizar neste contexto a importância da elaboração da subjetividade levando em conta que o lugar da aprendizagem (MAMEDE-NEVES, 2012), ou seja, a área de interseção entre a construção do real e a construção do sujeito, é favorecida pelo processo de desenvolvimento de um objeto projetado. Procuramos, assim, evidenciar que o ato de projetar deve receber atenção especial no ensino fundamental. Logo em seguida, estudamos o processo de tomada de consciência (PIAGET, 1978-79) como justificativa para a relevância da Aprendizagem baseada em Design durante o Ensino Fundamental, pois a partir deste conceito, fica claro que não é somente um objeto que conduz a criança à fase de compreensão. É necessário imaginar cenários ou problemas que favoreçam a criança a transformar os esquemas de ação prévios em apreensões de noções e operações. Se ela tem a oportunidade de brincar com os objetos, refletir sobre os resultados obtidos e ser desafiada com situações novas e multidimensionalmente planejadas, maior é a chance de ela estar desperta para os conceitos envolvidos e, assim, alcançar o nível de compreensão conceitualizada.

A partir de então, investigamos as aprendizagens ativas, tais como Aprendizagem baseada em Problemas (BARBOSA e MOURA, 2013) e Aprendizagem baseada em Projetos (HERNÁNDEZ, 2000; VENTURA, 1998), como propostas pedagógicas em sintonia com a formação de indivíduos com uma visão global da realidade, vinculando a aprendizagem a situações e problemas reais, preparando-o para a aprendizagem ao longo da vida. Após, fazemos uma análise das características da Aprendizagem baseada em Design (BAYNES, 2010), evidenciando-a como estratégia educativa que favorece a abordagem multidimensional apropriada à resolução problemas do mundo contemporâneo, que se realiza através de trabalho em equipe, que desenvolve a solução em cooperação com o usuário, que oportuniza a utilização de ferramentas de gestão e plano de ação - ambas importantes para a vida adulta, que é interdisciplinar, que aguça o senso estético e direciona-se à imaginar soluções esboçando ideias abstratas para ações futuras, ou seja, ativa a imaginação com um propósito específico.

\section{Premissas e pressupostos}

Partimos da premissa de que o Design articula conhecimentos dispersos, direcionando-os à solução de um problema complexo. Logo, a Aprendizagem baseada em Design favorece o pensamento multimensional e pode ser aproveitada como estratégia interdisciplinar de ensino-aprendizagem. Nosso pressuposto é de que esta estratégia deve ser incorporada à formação de professores como forma de garantir uma prática docente mais alinhada aos desafios da vida adulta contemporânea. 


\section{Estado da arte e ineditismo}

Várias pesquisas estrangeiras (DAVIS, 1997; BURNETTE, 2005; NELSON, 2006; dentre outros) já comprovam como a Aprendizagem baseada em Design já se incorpora ao cotidiano escolar. No Brasil, o LIDE PUC-Rio é pioneiro na investigação da Pedagogia do Design e da inserção do Design na Escola com os trabalhos de BUY, 1998; RIBEIRO, 2002; OLIVEIRA, 2009; PORTAS, 2013; PORTUGAL, 2010; MARTINS, 2007; COUTO, 1994, 2007, 2014, dentre outros. Há também outras pesquisas brasileiras que abordam esta temática: Tabak, 2012; FONTOURA, 2002; COUTINHO, 2008, 2011, dentre outras. Contudo, nenhuma destas pesquisas investiga possibilidades para a inserção da Aprendizagem baseada em Design na formação de professores. Vale ressaltar que o presente artigo é parte de um estudo mais amplo que objetiva investigar diferentes modos de utilizar a Aprendizagem baseada em Design no Ensino Fundamental através da inserção desta pedagogia na formação de professores capacitando-os, assim, a utilizar esta abordagem em suas práticas docentes.

\section{Relevância da pesquisa}

- Social: o Design e a Educação são duas atividades voltadas para o futuro. Assim sendo, através desta pedagogia os sujeitos poderão estar melhor preparados para lidar com desafios da complexidade.

- Pesquisa em Design: evidencia-se uma concepção do Design como um saber que vai além de uma abordagem procedimental: é um modo de conhecer e problematizar, um tipo de cognição. Esta abordagem favorece o entendimento de sua relação íntima com as ciências da Educação.

- $\quad$ Educação: a aprendizagem baseada em Design, tema desta pesquisa, desenvolve o pensamento flexível, a aprendizagem autônoma, favorece a autoavaliação, desenvolve a capacidade de comunicação interpessoal e o trabalho em equipe, promove cidadãos responsáveis com os outros e com o meio sociocultural, envolve os conhecimentos da vida cotidiana dos alunos e aumenta o conforto do aluno com a incerteza.

- Cultural: sujeitos formados a partir da Aprendizagem baseada em Design adquirem uma visão mais crítica a respeito da aparência e do discurso visual dos objetos. Isso implica um entendimento mais realista dos apelos do consumo, das subjetividades e formação de identidades, de questões de diferenciação a partir de estéticas, dentre outras tantas questões culturais.

\section{Paradigmas para a Educação contemporânea}

A Escola e a escolarização de sujeitos em grandes centros urbanos e em meio rural é objeto de diversas investigações e questionamentos que envolvem seu papel social, sua estrutura, seu funcionamento, sua história, seus sujeitos, somente para citar alguns enfoques. Entendemos que para estudar a pertinência da introdução da educação em Design na Escola antes é necessário compreender os pressupostos que fundamentam a existência desta instituição. Portanto, neste momento, faz-se importante uma caracterização do paradigma educacional contemporâneo, fato que nos ajudará a localizar oportunidades de inserção de projetos de Design na Escola.

Moraes (2005) comenta que, em linhas gerais, o cotidiano educacional contemporâneo apresenta-se como uma construção derivada da associação entre correntes de pensamento da cultura ocidental, destacando-se entre elas a Revolução Científica (séculos XVI e XVII), o Iluminismo e a Revolução Industrial. Estas derivações trouxeram benefícios como o desenvolvimento científico-tecnológico vigente, a democratização do conhecimento, a constituição de um espírito de investigação e validação científica. Por outro lado, é preciso levar em consideração o caráter reducionista do modelo científico clássico (racionalismo), que fragmenta a realidade para buscar seu entendimento, e, ao fazê-lo, impossibilita a visão da totalidade, como apontado 
por Morin (2007). Moraes enfatiza que a fragmentação da realidade é maior responsável pelas causas dos problemas educacionais atuais. Estes problemas são: uma grade compartimentada e fixa de conhecimentos, onde existe pouca conexão entre os saberes; a baixa valorização dos sujeitos no processo de ensino-aprendizagem e a supervalorização do ensino em detrimento à uma preocupação com a aprendizagem do aluno e uma valorização excessiva e destorcida do processo de avaliação que, em última análise, pauta-se numa aprovação no vestibular.

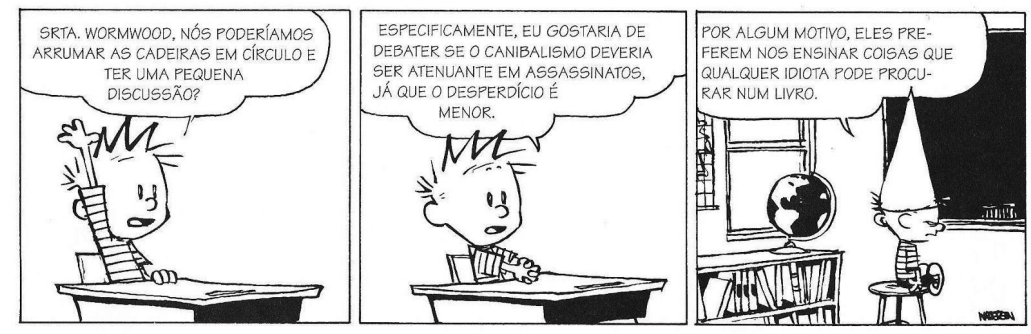

Figura 1 : Tirinha Calvin and Hobbes de Bill Watterson.

Moraes aponta que uma visão mais abrangente e emancipadora do processo de construção do conhecimento inaugura-se no final do século XIX, quando o paradigma newtoniano da ciência começa a ser posto em xeque. As inovações mais interessantes, conforme Moraes (2005), foram trazidas pelos pressupostos da mecânica quântica e da Teoria da Relatividade, que promovem uma renovação na visão das leis do universo relacionadas à matéria e ao movimento, trazendo o Princípio da Incerteza e aproximando a ciência às experiências de vida diárias. Estas teorias seriam capazes de esclarecer como ocorre a relação do sujeito com a construção do seu conhecimento, algo que está permanentemente em processo. Conforme Moraes, estas teorias esclarecem a interdependência entre ambiente geral e pensamento, uma vez que o ambiente flui para dentro do sujeito por meio da percepção humana evidenciando, assim, a teia de interações e relações existentes entre todos os fenômenos, fatos apontados também por Morin.

Conforme a análise de Moraes (2005), os problemas evidentes da prática educacional brasileira apresentam, ainda, fatores que envolvem decisões políticas, metodologias inadequadas e o apego a um modelo de construção do conhecimento obsoleto, pois está arraigado à teorias do conhecimento ultrapassadas. A proposição de solução proposta por Moraes envolve a renovação de perspectivas com base em práticas e teorias do pensamento Pós-Moderno, pois nessa visão os sujeitos aprendentes são apreciados multidimensionalmente de forma que não se privilegie somente a dimensão racional, mas também seu aspecto emocional, criativo e intuitivo.

O paradigma educacional emergente proposto por Moraes, em relação íntima com os postulados de uma Ciência renovada, envolve a concepção de novas missões para a Escola: encarar os sujeitos de forma singular, entendendo que possuem desejos e necessidades particularizados; valorizar as inteligências múltiplas e diferentes habilidades para resolver problemas; entender que os estilos de aprendizagem variam e que é necessário encontrar o que motiva cada aluno; compreender que o processo de aprendizagem é mais importante que metodologias de ensino e, ainda, fazer com que o aluno compreenda que o processo de reflexão e tomada de consciência é algo que lhe assegura emancipação e autonomia para mudar o que for preciso no processo particular de construção do conhecimento - aprender a aprender. Outro aspecto a salientar é a visão de que, mesmo valorizado, o sujeito precisa conviver e interagir com seus pares. Isso evidencia a questão da interdependência e da colaboração para a construção do conhecimento e da vida em sociedade. Entendemos que todos estes aspectos podem ser favorecidos pelo desenvolvimento de projetos de Design, como será explorado mais adiante. 
Sobre o papel do professor e do ambiente de aprendizagem: no paradigma emergente de Moraes, o professor é entendido como um pesquisador ativo e permanentemente atualizado, sujeito que possui um entendimento detalhado das necessidades de cada aluno, que atua buscando propostas curriculares e práticas educativas flexíveis. Um detalhe importante é a visão de que o contexto social da Escola (comunidade, bairro, adjacências) passa a ser concebido como suporte intelectual e fonte de problemas que exigem solução. Estas podem ser implementadas pelo coletivo de alunos, sujeitos ativos, através de enfoque multidisciplinar.

Moraes (2005) arremata sugerindo que o paradigma educacional emergente é de natureza construtivista, interacionista, sociocultural e transcendente. Construtivista, pois abarca o conhecimento como inacabado, em constante processo de construção e dependente da ação de sujeitos que o promovem e transformam. Interacionista, porque reconhece que o sujeito e o objeto são organismos vivos, abertos, ativos, em constante intercâmbio com o meio-ambiente. Sociocultural, pois considera que é na relação, no dialogismo, que os seres humanos se constroem, produzindo conhecimento na interação com o meio físico e social. Transcendente, pois evidencia a tentativa de ir além, superar-se, entrar em comunhão com a totalidade indivisível, compreender-se como parte integrante do universo, como seres interdependentes numa caminhada ao mesmo tempo individual e coletiva.

Ou seja, o paradigma educacional emergente evidencia um cenário propício à postulação de práticas de aprendizagem integradoras de conhecimentos multidimensionais, flexíveis, emancipadoras, colaborativas, atentas às necessidades do contexto próximo à escola. Este estudo fundamenta-se na ideia de que a integração de conhecimentos problematizados através de projetos de Design podem oportunizar essa demanda.

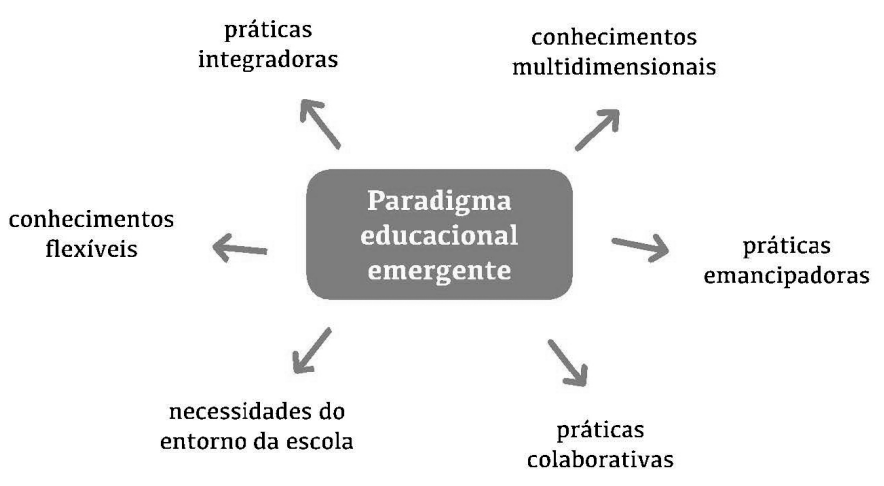

Figura 2: Paradigma educacional emergente segundo Moraes, 2005.

\section{Relações entre o projetar e a elaboração da subjetividade}

Para debater que o processo de Design favorece, ainda, um importante aspecto da aprendizagem, no que se refere à elaboração do mundo e do próprio eu, apontamos os estudos de Portas (2014), sobre práticas pedagógicas dinamizadas por meio de projetos de Design. Particularmente, nos interessa, neste estudo, o ponto onde a autora discute o lugar a aprendizagem, citando os estudos de Mamede-Neves (1996).

Conforme Winnicott (1975, apud PORTAS, 2014), uma experiência criativa começa a se desenvolver nos primeiros anos de nossas vidas na "área da experimentação", um espaço que não pertence à realidade interna nem à realidade externa, configurando-se como um espaço simbólico potencial construído entre o bebê e a mãe. Conforme o autor, ocorre uma evolução transicional entre a primeira possessão não-eu para o brincar, do brincar para o brincar compartilhado e daí para experiências culturais. É no brincar, e talvez apenas no brincar, que a criança ou adulto fruem sua liberdade de criação (WINNICOTT, 1974, 1979; apud PORTAS, 2014, 35). Conforme Portas (op.cit.), a imagem de um território livre para experimentação é a mesma que a do desenvolvimento de projetos em Design, posto que o objeto em configuração é resultado dessa experiência que articula as duas realidades (interna e externa). Essa articulação é fruto de um processo de pensamen- 
to que não somente se constitui na sintonia das diferentes dimensões do sujeito, como encontra estruturas de operação para fazer frente às situações dilemáticas. $\mathrm{O}$ ato de projetar, configurar objetos ou sistemas de comunicação, com ações diretas em nossa realidade externa, como fazemos no campo do Design, é resultante de um processo de criação interno, correspondendo a uma elaboração mental de antever, projetar uma ideia ou processo. É a partir dele que fazemos a transposição dessas ideias ou fantasias para o mundo físico, transpondo o que acreditamos ser possível ou exequível.

Esta experiência criadora é algo inerente ao ser humano e, neste ponto, recordamo-nos da citação de Marx referente à comparação entre a abelha e o arquiteto:

A abelha envergonha muitos arquitetos ao construir seus favos, mas o que distingue o pior arquiteto da melhor abelha é que o arquiteto ergue sua estrutura na imaginação antes de erigi-la na realidade, No final de todo o processo de trabalho, obtemos um resultado que, em princípio, já existia na imaginação do trabalhador. (MARX, 1985, p. 149)

Conforme Mamede-Neves (1996; apud PORTAS, 2014), através do seu desenvolvimento, o sujeito amplia o seu círculo de relações interpessoais, desenvolve e aprimora as trocas sociais, as estruturas afetivas e cognitivas, processando e introjetando suas experiências.

Os impulsos interiores e as exigências do contexto são poderosos construtores da nossa identidade. Mamede-Neves (op. cit.) aponta o conceito de sujeito cognoscente como resultado da interação entre as dimensões racional, desiderativa e relacional. Por isso, conforme a autora, não se pode pensar no trabalho pedagógico sem considerar como essas relações atuam e interagem permitindo que o sujeito do conhecimento emerja nessa integração.

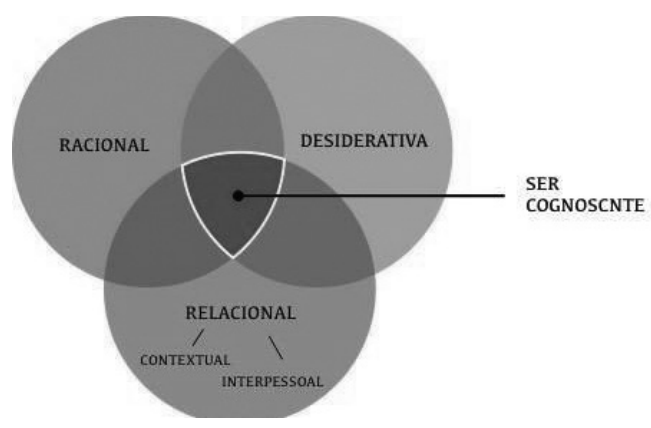

Figura 3: Síntese visual demonstrando a relação entre as dimensões racional, desiderativa e relacional - Mamede-Neves 1996; apud Portas, 2014.

Segundo Mamede-Neves (2012; apud PORTAS, 2014), o processo de reconhecimento e autodescoberta percorrido pelo aluno torna-se possível por meio da construção de seu objeto de projeto, elemento que articula as realidades interna e externa. A autora propõe, então, que o lugar da aprendizagem é a área de interseção entre a construção do real e a construção do sujeito, as quais operam ao mesmo tempo. Esta interseção atua como um centro processador entre essas duas construções e define os comportamentos que as pessoas vão ter no mundo. 


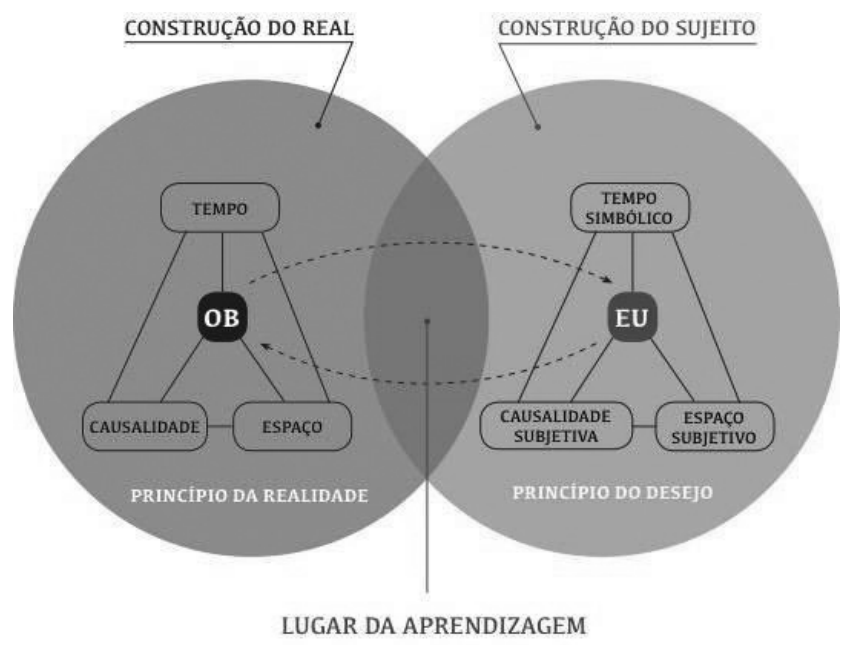

Figura 4: Lugar da aprendizagem por Mamede-Neves (2012).

Se o lugar da aprendizagem proposto por Mamede-Neves (op. cit.) é capaz de potencializar a construção do real e a construção do sujeito, e o que favorece esse processo é o desenvolvimento do objeto projetado, fica evidente que o ato de projetar, ou seja, prototipar ativando elaborações mentais para antever soluções para problemas específicos deve receber atenção especial no ensino fundamental.

Infelizmente, como aponta Baynes (2010), se o desenvolvimento cognitivo das crianças tem sido muito estudado, o mesmo não ocorre com igual proporção com o seu desenvolvimento criativo. A imaginação e a simulação são fundamentais para o desenvolvimento da criatividade humana. No entanto, não recebem o espaço merecido na Escola.

\section{O Design como processo que favorece a Tomada de Consciência}

Vejamos agora como o desenvolvimento de estratégias ou projetos de Design pode favorecer outro conceito importante do processo de aprendizagem. A Tomada de Consciência, conceito desenvolvido por Piaget, relaciona-se à compreensão das causas que levam ao sucesso das ações durante o processo de desenvolvimento dos sujeitos. Como exemplo, pode-se citar o caso de um aluno que executa várias atividades, as quais podem ou não ser realizadas com sucesso. $O$ fato de o aluno ter sido bem-sucedido não significa, necessariamente, que compreendeu o que fez. Piaget observou que há uma diferença entre o fazer com sucesso e o compreender o que foi feito. A compreensão conceitualizada, conforme Piaget $(1977 ; 1978)$, é o processo pelo qual crianças e adolescentes desenvolvem a compreensão a respeito consciência. Tal compreensão é alcançada graças a um processo de transformação de esquemas de ação em noções e operações. Desse modo, por uma série de coordenações de conceitos mais complexos, a criança pode passar do nível de sucesso prematuro para um nível de compreensão conceitualizada. Piaget demonstrou que a passagem do sucesso prematuro para a conceitualização é realizada em três fases: a primeira constitui-se na ação material sem conceituação: a criança pode atingir um objetivo, contudo ela negligencia todos os elementos envolvidos na tarefa; na segunda fase - da conceituação propriamente dita - há a tomada de consciência através da compreensão dos elementos da ação e a eles são acrescentados novos conceitos em relação ao esquema prévio: a criança coordena os elementos e sabe explicar os motivos do sucesso ou do fracasso; na terceira fase, conhecida como abstração refletida (reflexão do pensamento sobre si mesmo - 11/12 anos, aproximadamente), a criança coordena todos os elementos envolvidos na tarefa e é capaz de aplicá-los a novos contextos, fazendo planos para atingir o sucesso e explicando os prováveis motivos do fracasso. Neste ponto, vemos que desenvolver projetos de Design em suas diversas etapas onde há planejamento, tentativa e erro dentre outros, oportunizam a tomada de consciência. 


\section{O papel da interação na tomada de consciência}

Conforme Piaget (1977/78), a passagem da ação material para o pensamento como a interiorização dos atos, ou seja, a tomada de consciência, ocorre da periferia para o centro. A periferia de uma ação se refere ao que é externo ao sujeito e ao objeto, caracterizando-se como a interface onde ocorre a interação. $\mathrm{O}$ centro da ação seria a consciência do sujeito e as propriedades intrínsecas do objeto. Conforme Piaget, a tomada de consciência ocorre da observação dos objetivos e resultados (periferia) até alcançar o reconhecimento dos meios empregados e os motivos de sua escolha (centro). Em outras palavras, a tomada de consciência orienta-se para os mecanismos centrais da ação do sujeito, e o conhecimento do objeto orienta-se para o reconhecimento pelo sujeito de suas propriedades intrínsecas. Neste ponto, vale ressaltar que determinar um objetivo frente a um objeto já é assimilar este objeto a um esquema prático.

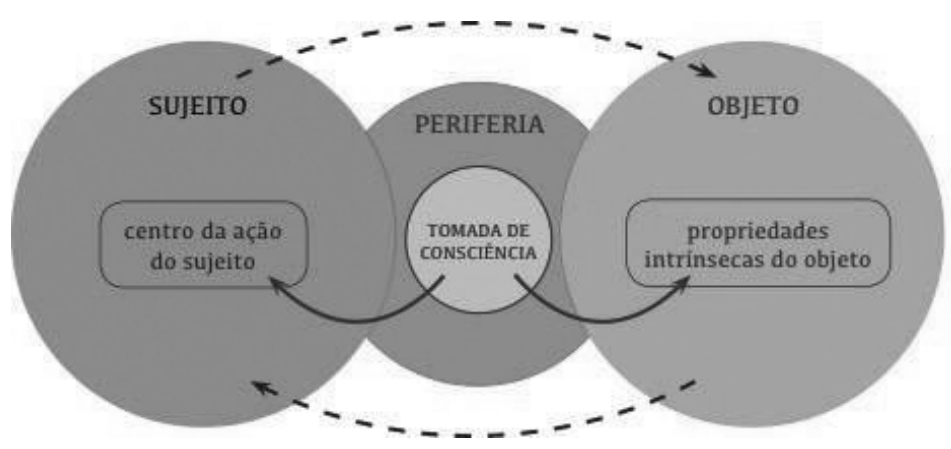

Figura 5: O processo de Tomada de Consciência, conforme Piaget, 1977.

Ao comentar sobre a interação entre sujeito e objeto durante a tomada de consciência, Piaget destaca o processo de interiorização que leva à construção das estruturas lógicas interpretativas das ações, ou seja, teorizar sobre as ações; e o processo de exteriorização que leva à elaboração das explicações materiais/físicas, ou seja, as causas/explicações dedutivas das ações sobre os objetos. Para completar, Piaget (1978) argumenta que existe uma relação de solidariedade entre o sujeito e o objeto: o sujeito aprende a se conhecer mediante a ação sobre os objetos, e os objetos se tornam cognoscíveis em função do progresso das ações do sujeito sobre eles.

Os aportes da tomada de consciência desenvolvida por Piaget são importantes para o estudo da relevância da aprendizagem do Design na Escola, pois a partir daqui fica evidente que não é somente o objeto, ou qualquer objeto, que conduz a criança à fase de compreensão. É necessário imaginar cenários ou problemas que favoreçam a criança a transformar os esquemas de ação prévios em apreensões de noções e operações. Piaget notou que a compreensão/conceitualização é fruto da qualidade da interação entre a criança e o objeto/situação. Se ela tem a oportunidade de brincar com os objetos, refletir sobre os resultados obtidos e ser desafiada com situações novas e multidimensionalmente planejadas, maior é a chance de ela estar desperta para os conceitos envolvidos e, assim, alcançar o nível de compreensão conceitualizada.

Estas últimas observações são fundamentais para entender as frutíferas relações que devem acontecer entre alunos e os objetos e para caracterizar as situações que precisam fazer parte do seu ambiente de aprendizagem. Essas novas relações determinam novos papéis que deverão ser assumidos pelos diferentes profissionais que atuam na escola, incluindo Designers. Essa mudança deve valer não só para as pessoas, mas também para a qualidade das interações que os alunos precisam ter com os objetos e atividades realizadas. A sutileza desta abordagem aponta que não é apenas o fazer algo para chegar a uma resposta. Mais relevante do que isso é a interação com o que está sendo feito, de modo a permitir as transformações dos esquemas mentais, como observado por Piaget. Por outro lado, podemos destacar que os objetos e atividades precisam ser estimulantes para que o aluno possa estar envolvido com o que faz. Estes devem ser ricos em oportunida- 
des para permitir ao aluno explorá-las e possibilitar aberturas para o professor desafiar o aluno e, com isso, incrementar a qualidade da interação com o que está sendo feito.

\section{As aprendizagens ativas: aprender fazendo}

$\mathrm{Na}$ intenção de esmiuçar o campo das atividades educativas estimulantes, envolventes e que promovem interações propositivas e a construção de novos entendimentos, chegamos ao território das aprendizagens ativas. Neste aspecto, interessa a esse estudo traçar um paralelo estabelecendo proximidades e diferenças entre as distintas modalidades de aprendizagem ativa, tais como: aprendizagem baseada problemas (ABProb) e a aprendizagem baseada projetos (ABProj), tentando esclarecer suas afinidades com a Aprendizagem Baseada em Design.

\section{Sobre o conceito de aprendizagem ativa}

Conforme Barbosa e Moura (2013), a expressão aprendizagem ativa, que pode ser entendida também como aprendizagem significativa, é comumente usada de forma vaga e imprecisa. Segundo os autores, intuitivamente, professores imaginam que toda aprendizagem é inerentemente ativa. No entanto, os pesquisas da ciência cognitiva sugerem que os alunos devem fazer algo mais do que simplesmente ouvir para ter uma aprendizagem efetiva (MEYERS; JONES, 1993, apud Barbosa e Moura, 2013). Para se envolver ativamente no processo de aprendizagem, o aluno deve ler, escrever, perguntar, discutir ou estar ocupado em resolver problemas e desenvolver projetos. Além disso, o aluno precisa realizar tarefas mentais de alto nível, como análise, síntese e avaliação. Nesse sentido, as estratégias que promovem a aprendizagem ativa são aquelas que induzem o aluno a fazer alguma coisa ao mesmo tempo levando-o a pensar sobre as coisas que está fazendo. Neste sentido, encontramos uma conexão com as ideias de Piaget já apresentadas, uma vez que o conceito de aprendizagem ativa ocorre quando o aluno interage com o assunto em estudo - ouvindo, falando, perguntando, discutindo, fazendo e ensinando - sendo estimulado a construir o conhecimento ao invés de recebê-lo do professor de forma passiva.

O papel do professor em um ambiente de aprendizagem ativa é o de atuar como orientador do processo de aprendizagem e não apenas como fonte única de informação e conhecimento. Independentemente do método ou da estratégia usada para promover a aprendizagem, a diferença fundamental que caracteriza um ambiente de aprendizagem ativa é a atitude ativa da inteligência, em contraposição à atitude passiva geralmente associada aos métodos tradicionais de ensino.

Ainda segundo Barbosa e Moura (2013), para o aluno, tão importante quanto pensar no que está fazendo, é sentir o que está fazendo. Conforme os autores, a participação dos sentimentos deve ser vista como um fator relevante na construção do conhecimento. Logo, o bom humor, a boa disposição e a alegria são os lubrificantes das engrenagens do entendimento e da aprendizagem (BARBOSA e MOURA, 2013).

\section{Aprendizagem Baseada em Problemas - ABProb}

Aprender a partir de problemas propostos de forma didática é uma estratégia bem antiga. Diz-se que o filósofo Confúcio (500 a.C.) só ajudava a seus seguidores na resposta a algum problema ou questão depois que eles tivessem feito algum esforço próprio na busca da solução. Conforme Araújo (2011), a sistematização da metodologia de Aprendizagem Baseada em Problemas, como é conhecida hoje, surgiu na década de 1960 no Canadá, onde foi aplicada inicialmente em escolas de Medicina. Apesar da aplicação inicial na área médica, esta estratégia tem sido utilizada em várias outras áreas do conhecimento, como administração, arquitetura, ciências da computação, ciências sociais, economia, engenharias e matemática. No Brasil, há interesse crescente por essa metodologia, e algumas escolas a aplicam regularmente em seus cursos, como é o caso da Escola de Artes, Ciências e Humanidades da Universidade de São Paulo - EACH/USP. (ARAÚJO, 2011). 
Esse método de ensino fundamenta-se no uso contextualizado de uma situação-problema para o aprendizado autodirigido. Enquanto que nos métodos convencionais o objetivo é a transmissão do conhecimento centrada no professor em conteúdos disciplinares, na Aprendizagem Baseada em Problemas, o aprendizado passa a ser centrado no aluno, que deixa de ser um receptor passivo da informação para ser agente ativo em seu aprendizado. Nesse contexto, o professor atua como orientador nos grupos de trabalho ou estudo, nos quais a interação entre professor-aluno é muito mais intensa do que em aulas puramente expositivas. Esta modalidade de aprendizagem admite sequências de trabalho que podem variar conforme o nível e tipo de ensino, com a área do conhecimento e com os objetivos de aprendizagem que se quer alcançar. Em linhas gerais, ABProb inclui as etapas mostradas na figura a seguir - Barbosa e Moura (2013).

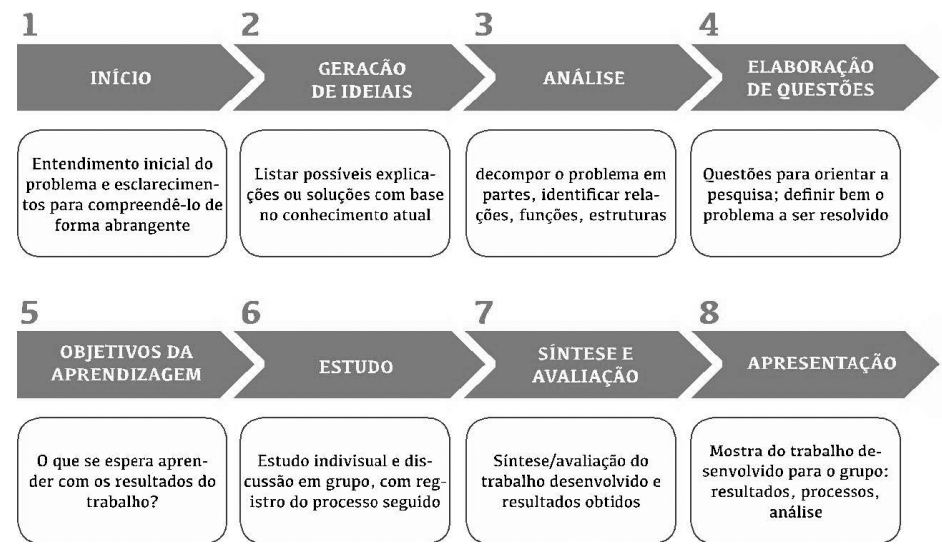

Figura 6: Etapas da aplicação da ABProb - Araújo, 2011.

Vale destacar que, em cada etapa de aplicação da Aprendizagem Baseada em Problemas, o aluno desempenha tarefas que favorecem a assimilação e construção do conhecimento, partindo do entendimento inicial do problema proposto, passando pelas fases de análise e busca de uma solução até a apresentação do trabalho e análises dos resultados. Esta estratégia utiliza um problema como base de motivação para o aprendizado autodirigido, dando ênfase à construção do conhecimento em ambiente de colaboração mútua. A resolução do problema é menos importante do que o processo seguido pelo grupo na busca de uma solução, e este fator valoriza a aprendizagem autônoma e cooperativa, ou seja, valoriza-se a interação com o que está sendo feito, conceito alinhado às ideias de Piaget.

Uma vez que a Aprendizagem Baseada em Problemas difere muito dos métodos convencionais de aprendizagem, é de se esperar que tanto os professores como os alunos assumam funções diferentes das que estão acostumados no ensino convencional. O quadro a seguir ilustra algumas dessas diferenças - Barbosa e Moura (2013): 


\begin{tabular}{|l|l|l|}
\cline { 2 - 3 } \multicolumn{1}{c|}{} & \multicolumn{1}{c|}{ Ensino convencional } & \multicolumn{1}{c|}{ Abordagem da ABProb } \\
\hline \multirow{3}{*}{} & Funçäo de especialista ou autoridade formal & Orientador, coaprendiz ou consultor \\
\cline { 2 - 3 } & Trabalho isolado & Trabalho em equipe \\
\cline { 2 - 3 } & Transmissor de informação aos alunos & Ensina o aluno a gerenciar sua aprendizagem \\
\cline { 2 - 3 } & Conteudo organizado em aula expositiva & Curso organizado a partir de problemas reais \\
\cline { 2 - 3 } & Trabalho individual por disciplina & Estimulo ao trabalho interdisciplinar \\
\hline
\end{tabular}

\begin{tabular}{|l|l|l|}
\hline Receptor passivo da informação & Valorização do conhecimento prévio \\
\hline Trabalho individual isolado & Interação com colegas e professores \\
\hline Transcrevem, memorizam, repetem & Função de bustar/construir o conhecimento \\
\hline Aprendizagem individualista e competitiva & Aprendizagem em ambiente colaborativo \\
\hline Busca a resposta certa para se sair bem na prova & Busca questionar e equacionar problemas \\
\hline Avaliação dentro de conteúdos limitados & Análise e solução ampla de problemas \\
\hline Avaliação somativa e só o professor avalia & o aluno e o grupo avaliam contribuiçōes \\
\hline Aula baseada em transmissão da informação & $\begin{array}{l}\text { Trabalho em grupo para buscar soluções; } \\
\text { Conhecimento aplicada em vários contextos; } \\
\text { Busca da informação com orientação docente }\end{array}$ \\
\hline
\end{tabular}

Quadro 1: Requisitos para professor e aluno no ensino convencional e na ABProb - Barbosa e Moura (2013).

\section{Papel do professor e da escola na Aprendizagem Baseada em Problemas}

Uma vez que este estudo dedica-se a investigar a formação de professores numa abordagem que integra estratégias de Design ao processo de aprendizagem, vale a pena tomar conhecimento dos papéis do professor e da escola numa aprendizagem ativa. Nesta perspectiva, exigem-se novas posturas para o professor: mediar discussões, atuar para manter grupos de alunos focados em um problema/questão específica, motivar alunos a se envolverem com as tarefas requeridas no processo de busca de solução e estimular o uso da função de pensar, observar, raciocinar e entender. Isso significa que o professor precisa ativar a própria inteligência para atuar de forma propositiva, integradora, motivadora e mediadora de tal maneira que seu exemplo sirva de inspiração para o aluno.

Contudo, proporcionar uma abordagem centrada no aluno e não no professor, demanda adequações de espaço e tempos escolares diferenciados em relação às práticas tradicionais de ensino. Salienta-se a necessidade de investimento na formação e capacitação dos professores, como também do próprio corpo técnico e administrativo e, em muitos casos, na infraestrutura da escola. Ainda, implementar uma Aprendizagem Baseada em Problemas pode requerer adequação de mobiliário e equipamentos próprios que favoreçam trabalhos e discussões em grupos informais e a mobilização de espaços fora da sala de aula. O aluno deve se sentir motivado a buscar material de apoio, seja no interior da instituição (laboratórios, bibliotecas, etc.), seja no ambiente externo a ela. Até mesmo a disposição do mobiliário nas salas de aula pode influenciar no desempenho do aluno na aplicação das metodologias ativas (RIBEIRO, 2005; BARBOSA e MOURA, 2013).

\section{A Aprendizagem Baseada em Projetos - ABProj}

No senso comum é possível dizer que projetos são empreendimentos finitos com objetivos bem definidos que nascem a partir de um problema, uma necessidade, uma oportunidade ou interesses de uma pessoa, um grupo de pessoas ou uma organização. Segundo Barbosa e Moura (2013), quanto à tipologia, os projetos podem ser do tipo intervenção, desenvolvimento, pesquisa, ensino e aprendizagem. A ideia de trabalhar com 
projetos como recurso pedagógico na construção de conhecimentos remonta ao final do século XIX, a partir de ideias enunciadas por John Dewey, em 1897. No entanto, uma importante referência para o trabalho com a Metodologia de Projetos remonta ao final do século XVII na Itália, sob uma perspectiva de ensino na área da arquitetura e mais tarde engenharia mecânica. Contudo, John Dewey e William H. Kilpatrick, ambos do início do século XX, são considerados os precursores da Aprendizagem Baseada em Projetos. Na visão de Kilpatrick, o projeto com fins educacionais teria quatro fases essenciais: intenção, planejamento, execução e julgamento. Diferentemente de Kilpatrick, na visão de Dewey, os projetos realizados por alunos demandam necessariamente a ajuda de um professor que possa assegurar o processo contínuo de aprendizagem e crescimento.

Um detalhe importante que ajuda a distinguir a pedagogia por projetos é sua vocação de abordar situações reais relativas ao contexto e à vida, no sentido mais amplo. É desejável também que essas situações-problema reais sejam escolhidas/identificadas pelo autor do projeto em desenvolvimento.

Desse modo, a aprendizagem baseada em projetos reais é uma aprendizagem significativa, pois esta

se verifica quando o estudante percebe que o material a estudar se relaciona com os seus próprios objetivos. [...] É por meio de atos que se adquire aprendizagem mais significativa. A aprendizagem é facilitada quando o aluno participa responsavelmente do seu processo. A aprendizagem auto-iniciada que envolve toda a pessoa do aprendiz - seus sentimentos tanto quanto sua inteligência - é a mais durável e penetrante (GADOTTI, 1994, p.19).

Segundo Hernandéz e Ventura (1998), a pedagogia por projetos propõe a formação de indivíduos com uma visão global da realidade, vinculando a aprendizagem a situações e problemas reais, preparando para a aprendizagem ao longo da vida. Ainda conforme esses autores, a expressão aprendizagem por projetos se refere à formulação de questões pelo autor do projeto, pelo sujeito que vai construir conhecimento. É a partir do conhecimento prévio que o aprendiz vai se movimentar e interagir com o desconhecido, ou com novas situações, para se apropriar do conhecimento. Um projeto de aprendizagem deve ser gerado pelos conflitos, pelas perturbações no sistema de significações, que constituem o conhecimento particular do aprendiz. A escolha das variáveis que vão ser testadas na busca de solução de qualquer problema precisa ser sustentada por um levantamento de questões feitas pelo aluno. As dúvidas e o interesse em buscar as respostas, princípios geradores do projeto de aprendizagem, deve ser tarefa do aluno, enquanto está em atividade num determinado contexto, em seu ambiente de vida, ou numa situação enriquecida por desafios (HERNANDÉZ, 2000; VENTURA, 1998).

Para Hernández (2000), um projeto pode ser considerado:

1. O percurso por um tema-problema que favoreça a análise, a interpretação e a crítica (como contraste de pontos de vista);

2. Uma situação em que predomine a atitude de cooperação e em que o pro-fessor seja um aprendiz e não um especialista (pois ajuda aprender sobre temas que deverá estudar com os alunos);

3. Um percurso que procure estabelecer conexões e que questione a ideia de uma versão única da realidade;

4. Uma trajetória singular, em que se trabalha com diferentes tipos de informação;

5. Uma estratégia onde se aprenda a escutar pois o discurso alheio pode mudar o rumo do estudo;

6. Uma perspectiva onde fique evidente que há diferentes formas de aprender e que esteja aberta a aprendizagem de questões imprevisíveis pelo professor;

7. Uma aproximação atualizada aos problemas das disciplinas e dos saberes;

8. Uma forma de aprendizagem em que se leve em conta que todos podem aprender se encontrarem espaço para isso;

9. Uma perspectiva de que a aprendizagem vinculada ao fazer, à atividade manual e à intuição também é uma forma de aprendizagem. 
Vale a pena destacar que, em relação à vocação para abordar situações concretas, a aprendizagem baseada em projetos faz uma intencional oposição à dimensão excessivamente virtual (simulação não concreta) nos ambientes educacionais. Conforme Godoy (2009), é possível dizer que a pedagogia por projetos pode ser uma forma valiosa de compensar problemas decorrentes do uso exagerado de recursos virtuais - como a utilização de softwares educativos para simulação de situações da vida real - em detrimento de situações reais e contextuais. Já verificamos, através dos estudos de Mamede-Neves e Piaget, que a formação do ser humano, em caráter integral, demanda o desenvolvimento de um equilíbrio fundamental entre fatores relativos à abstração racional a fatores relativos ao desenvolvimento sensível e sensório-motor. Por isso, a proposta de aprendizagem baseada em projetos reais representa uma forma importante de considerar todos os elementos referentes à formação integral do ser humano (BARBOSA e MOURA, 2013).

É esboçado a seguir um quadro comparativo entre a Aprendizagem Baseada em Problemas e a Aprendizagem Baseada em Projetos (BARBOSA e MOURA, 2013).

\begin{tabular}{|c|c|}
\hline Aprend. Baseada em Problemas & Aprend. Baseada em Projetos \\
\hline Tem oriegem em problemas & $\begin{array}{l}\text { Situação-geradora (problemas, necessidades, oportuni- } \\
\text { dades, interesse): }\end{array}$ \\
\hline Problema: mais contextual que teórico & Situaçäo geradora: contextual ou teórica \\
\hline $\begin{array}{l}\text { Problemas definidos pelo professor (garante cober- } \\
\text { tura de conteúdos de interesse do curso/professor); }\end{array}$ & $\begin{array}{l}\text { Situacáo geradora definida pelos alunos mediados pelo } \\
\text { professor (maior potencial de motivaçâo dos alunos); }\end{array}$ \\
\hline Curta duração ( 2 a 4 semanas) & Media duração (4 a 12 semanas) \\
\hline percurso com etapas bem definidas & Percurso com etapas abertas e flexíveis \\
\hline Proposta de análise/solução de um problema & Proposta de desenvolvimento de algo novo \\
\hline Produto final năo obrigatório & Requer um produto final \\
\hline \multicolumn{2}{|c|}{ Formaçăo efetiva para o mundo do trabalho } \\
\hline \multicolumn{2}{|c|}{ Favorece a aprendizagem contextualizadae significativa } \\
\hline \multicolumn{2}{|c|}{ Requer disposição e habilidades especificas do professor e do aluno } \\
\hline \multicolumn{2}{|c|}{ Método de ensino centrado no aluno } \\
\hline \multicolumn{2}{|c|}{ Favorece a interdisciplinaridade } \\
\hline Favorece o desenvolvime & to da criatividade e inovaçấo \\
\hline
\end{tabular}

Quadro 2: Comparação entre os métodos ABPlob e ABProj - Barbosa e Moura (2013).

\section{Considerações finais: o propósito de desenvolver a Aprendizagem Baseada em Design na Escola}

Após investigar os contornos e as propriedades das aprendizagens ativas, tem-se uma base para salientar que a natureza das atividades desenvolvidas durante um processo de Design também pode enquadrar-se como um tipo especial de aprendizagem ativa. A Aprendizagem Baseada em Projetos de Design como estratégia educativa favorece a abordagem multidimensional apropriada à resolução de problemas do mundo contemporâneo, realiza-se através de trabalho em equipe, desenvolve a solução em cooperação com o usuário, oportuniza a utilização de ferramentas de gestão e plano de ação, ambas importantes para a vida adulta, é interdisciplinar, aguça o senso estético e direciona-se à imaginar soluções esboçando ideias abstratas para ações futuras, ou seja, ativa a imaginação com um propósito específico. Vejamos, conforme o estudo de Baynes (2010), mais alguns pontos favorecidos pela Aprendizagem Baseada em Design.

1. Objetivos da Aprendizagem Baseada em Design:

- Proporcionar desafios aos alunos e professores como uma estratégia divertida e gratificante 
de trabalhar e estar junto;

- Oferecer a cada criança a oportunidade de aprender sobre Design e desenvolver projetos dentro de seu próprio nível de aprendizagem;

- Oferecer aos alunos com especial aptidão para o Design a oportunidade de desenvolver a sua capacidade como base para uma possível carreira relacionada ao Design, engenharia, arte ou tecnologia;

- Garantir a cada criança a aprendizagem de habilidades em Design e conhecimentos relevantes para a vida adulta, particularmente atividades como: organização do meio ambiente, da casa, auto-expressão e participação social;

- Destacar a importância da aprendizagem de questões relacionadas ao meio-ambiente e ao meio construído, conectando o ensino do Design com a educação para o consumo consciente.

2. Valorizar a aprendizagem prática;

3. Incentivar a imaginação;

4. Desenvolver a consciência estética;

5. Aprender fazendo: desenvolver o pensamento projetual e a habilidade construtiva;

6. Compreender como as atividades de projetar e prototipar afetam a vida diária e questões ambientais e tecnológicas que a sociedade enfrenta.

Por fim, o estudo de Baynes contribui significativamente para o entendimento dos propósitos e da validade da Educação em Design no ensino fundamental. Conforme o autor, o raciocínio em Design potencializa um currículo orientado aos desafios do futuro contribuindo para o desenvolvimento da capacidade de lidar criativamente com os problemas econômicos, ambientais e sociais. Como Bruce Archer acreditava, a incorporação da Educação em Design no ensino básico contribui para "a sobrevivência próspera" da humanidade.

Por isso, a natureza do Design, seus princípios, metodologias, interações e práticas estudados ao longo desta investigação nos dão ideia da pertinência de sua apropriação no contexto escolar brasileiro como estratégia projetual integradora de conhecimentos multidimensionais, como meio de inter-relacionar professores e alunos e orientá-los no processo emancipatório de buscar soluções para problemas autênticos de seu contexto (comunidade, região, etc.). Nos parece bastante evidente, agora, que desenvolver aprendizagens ativas onde haja a interação, a prototipagem e/ou desenvolvimento de objetos ou sistemas de comunicação amplia, também, o desenvolvimento da construção mental de subjetividades e a tomada de consciência. Como desdobramento para novas pesquisas na intenção de amadurecer o conceito e a prática da Aprendizagem Baseada em Projetos de Design seria oportuno, portanto, avaliar cases já existentes sobre uso do Design na escola, seja como estratégia de integração de conhecimentos através do desenvolvimento de projetos de Design ou sua inserção como disciplina na grade curricular do ensino fundamental.

\section{Referências Bibliográficas}

ARAÚJO, U. 2013. A quarta revolução educacional: a mudança de tempos, espaços e relações na escola a partir do uso de tecnologias e da inclusão social. ETD: educação temática digital, Campinas, v. 12, 2011. Número especial. Disponível em: http://ojs. fe.unicamp.br/. Acesso em: 16 jul. 2013.

BARBOSA, E. MOURA, D. 2013. Metodologias ativas de aprendizagem na Educação Profissional e Tecnológica. In: Boletim Técnico. Senac, Rio de Janeiro, v. 39, n. 2, p.48-67, maio/ago.

BAYNES, K. 2010. Models of Change: The future of design education. In: Design and Technology Education: An International Journal. Loughborough, Vol. 15, No. 3, pgs. 10-17.

PORTAS, R. 2014. Desafios e perspectivas no ensino de design: experiência em disciplinas de projeto na PUC-Rio. 2014. Tese (Doutorado em design) - Departamento de Artes e Design - Pontifícia Universidade Católica do Rio de Janeiro, PUC-Rio, Rio de Janeiro, Brasil.

GADOTTI, M. 1994. Organização do trabalho na escola. 2.ed. SÃO PAULO: Ática.

HERNANDEZ, F.; VENTURA, M. 1998. A organização do currículo por projetos de trabalho. Porto Alegre: Artmed. 
HERNÁNDEZ, F. 2000. Cultura visual, mudança na educação e projetos de trabalho. Porto Alegre: ArtMed. MORAES, M. 2006.O paradigma educacional emergente. Campinas: Papirus. MORIN, E. 2007. Introdução ao pensamento complexo. Porto Alegre: Sulina. PIAGET, J. 1977. A tomada de consciência. São Paulo: Melhoramentos.

PIAGET, J. 1978. Fazer e compreender. São Paulo: Melhoramentos; EDUSP. 